\title{
Audit of bladder neck resection in spinal cord injured patients
}

\author{
F Derry ${ }^{1}$ and $S$ Al-Rubeyi ${ }^{2}$ \\ ${ }^{1}$ The National Spinal Injuries Centre, Stoke Mandeville Hospital, Aylesbury, Bucks HP21 8AL, UK; \\ ${ }^{2}$ Ibn Al-Kuff Spinal Injuries Hospital, Baghdad, Iraq
}

\begin{abstract}
An audit was carried out at Ibn Al-Kuff Spinal Injuries Hospital, Baghdad, Iraq, to try to establish the value of bladder neck resection in the neuropathic bladder of spinal injured patients. Spinal cord injured men who underwent bladder neck resection and/or external sphincterotomy were identified and their bladder management and post-operative outcome was reviewed. some patients were available for objective assessment with urodynamics. Results of this procedure are discussed. Blind bladder neck resection, ie without prior urodynamic appraisal, was found to be useless in achieving bladder management goals.
\end{abstract}

Keywords: bladder neck; resection; neuropathic bladder; spinal cord injury; urodynamics

\section{Introduction}

Neuropathic bladder dysfunction following SCI is of great importance. Appropriate management has been critical in drastically lowering the rate of renal related deaths and morbidity in these patients. ${ }^{1}$ High pressure voiding systems and high storage pressure due to high urethral closure pressure is believed to cause deterioration of bladder form and function. ${ }^{2}$

Ibn Al-kuff spinal injuries centre was the first spinal unit in Iraq and was opened in 1982. Prior to the establishment of the urodynamic laboratory at the hospital, the approach to the management of the neuropathic bladder was somewhat empirical and speculative, and many patients underwent bladder outlet surgical procedures without objective assessment. Even after urodynamic examinations became available in 1988, their diagnostic value was often ignored. An objective assessment of the clinical value of these blindly performed procedures without the benefit of urodynamics in achieving their intended neuropathic bladder management goals was required, hence this audit was conducted.

\section{Patients and methods}

During the early months of 1989, 31 men with spinal cord injuries (SCI), who underwent bladder neck resection (BNR) and/or external sphincterotomy (ES) during the period from 1983-1988, were identified from the medical records at Ibn Al-Kuff spinal injuries hospital. Seven were inpatients undergoing rehabilitation for their spinal cord injury, 22 were outpatients undergoing regular 6 monthly or annual follow-up checks, and two were already dead. Their bladder management and post-operative outcome was identified

Correspondence: F Derry and studied. Nine patients were available for assessment with cystouroflowmetry and urethral pressure profilometry (UPP).

Four patients had urodynamic studies pre and post BNR, and another five patients had urodynamic studies after ES following initial BNR in addition to pre and post BNR urodynamics. All patients were young men with an age range of $19-43($ mean $=28)$. Although all patients had consented to undergo these procedures, fertility issues were not discussed.

The bladder outlet surgical procedures were carried out following so called 'failure of bladder training'. Successful bladder training was defined as achieving reflex trigger voiding for upper motor neurone cord lesions, and by straining or crêde manoeuvre for lower motor neurone lesions. Penile urinary sheaths were usually worn if this training is established. Repeated residual urine volume measurements using catheters, were used as a yardstick. An arbitrary $20 \%$ of the bladder capacity or $80 \mathrm{ml}$, whichever is smaller, was considered as an 'acceptable' residual volume. Six monthly IVU was carried out for monitoring the upper urinary tract.

At the end of the initial spinal shock period following SCI, during which nearly all patients had indwelling urethral catheters, repeated clamping and releasing of these catheters were tried associated with tapping or other triggering manoeuvres. If patients did not achieve successful bladder training as described, they were offered bladder outlet surgery as an alternative to permanent indwelling catheterisation. Intermittent catheterisation (IC) was seldom considered before 1988. Since early 1989, thanks to a dedicated catheter team run by nurses and supervised by a doctor, IC became available and many inpatients were treated by this method and some were taught to carry out their own intermittent self catheterisation. 
BNR involved removal of tissue around the internal meatus to the verumontanum $(5-8 \mathrm{gm}$ of tissue). ES involved making two posterolateral cuts just proximal to the verumontanum down to $3 \mathrm{~cm}$ distally, but not necessarily deep enough to reach the venous sinuses plane. A diathermy resectoscope loop was used instead of Colling's knife. No simple bladder neck incision was done, nor anteromedial ES was practised. These choices were quite empirical. Urodynamic studies were either not available or ignored in taking the decision to subject the patients for BNR and/or ES.

Cystouroflowmetry was conducted in the supine position, with slow to medium filling rates $(20-40 \mathrm{ml} /$ min) at room temperature $\left(25-28^{\circ} \mathrm{C}\right)$. A Disa 2100 machine, and later Dantec 5500, were used. Subtracted pressures were recorded. Anal or urethral spincter EMG was monitored during cystouroflowmetry using surface electrodes (anal plug or sponge), and a concentric needle was used only in lower motor neurone lesions. Double lumen $8 \mathrm{~F}$ catheters were used for cystometry and UPP which was carried out using the Brown-Wickham technique at a filling rate of $2 \mathrm{ml} / \mathrm{min}$ and $1 \mathrm{~mm} / \mathrm{sec}$ withdrawal rate. Cystouroflowmetry and UPP were repeated at least three times in any single session. Gentamycin $80 \mathrm{mg}$ IM/IV was given as a prophylactic antibiotic. Some patients had micturating cysto-urethrograms separately from urodynamics to identify vesico-ureteric reflux.

In group I, we identified 17 patients at different levels of neurological deficit, that have undergone $\mathrm{BNR}$ as a primary procedure to treat their so called 'failure in bladder training' (Table 1). Two patients had repeat $\mathrm{BNR}(\mathrm{MN}$ and $\mathrm{AH})$.
In group II, 12 other patients were subjected to an initial BNR, which failed in all of them to achieve balanced voiding or the so called 'successful bladder training' as defined earlier. They were offered ES in an attempt to achieve the same goal (Table 2). All 12 had normal upper tracts at the time of assessment.

Group III comprised of only two patients that underwent ES without BNR. Both managed to achieve balanced reflex voiding (Table 3 ).

Thirty-one procedures were carried out on 29 patients of varying neurological levels and deficits. All procedures were oblivious of urodynamic findings, or carried out in the absence of such examinations.

\section{Results}

BNR failed to achieve the stipulated goal, ie balanced voiding, in 27 out of 29 patients. This is a failure rate of $93.1 \%$. The two apparent successes are questionable. Two deaths were renal failure related shortly after BNR in high pressure voiding systems associated with reflux and bilateral hydronephrosis. Twenty patients ended with indwelling or suprapubic catheters, 15 after BNR and five after ES following BNR.

In group I patients (17) who underwent BNR only, 11 patients ended with permanent indwelling urethral or suprapubic catheters post BNR. Four patients developed vesico-ureteric reflux and hydronephrosis, two of whom died of renal failure several months post BNR (JD and $\mathrm{HH}$ ). One patient (MN) achieved reflex voiding 6 months post repeat BNR during which he was on Distigmine bromide for 4 months. Another patient (NO) managed to attain balanced strainer voiding 7 months post BNR. Both patients were not

Table 1 Group I SCI patients who underwent bladder neck resection (BNR) only

\begin{tabular}{|c|c|c|c|c|c|}
\hline Name & DOI & Level & $B N R$ & Result & Outcome/follow-up \\
\hline IS & 060384 & T6A & 120884 & Failed & Indwelling urethral catheter, ES was suggested \\
\hline JR & 150781 & T6A & 241085 & Failed & Suprapubic catheter \\
\hline MH & 071182 & T7A & 111283 & Failed & Suprapubic catheter, Urethral Stricture, lost to Follow-up \\
\hline \multirow[t]{2}{*}{ MN } & 260781 & T8A & 150683 & Failed & \\
\hline & & & 281283 & Success & Balanced reflex tapper after 4 months of Distigmine post-op \\
\hline SA & 080483 & T9A & 301183 & Failed & Unbalanced reflex tapper, Bilat. Hydronephrosis* \\
\hline JD & 070183 & T10B & 230483 & Failed & Unbalance reflex tapper, Bilat. Hydronephrosis*† \\
\hline \multirow[t]{2}{*}{$\mathrm{AH}$} & 171083 & $\mathrm{~T} 10 \mathrm{C}$ & 100684 & Failed & \\
\hline & & & 270585 & Failed & Indwelling urethral catheter, ES was suggested \\
\hline AT & 090283 & T11A & 310883 & Failed & Unbalanced strainer, Bilat. Hydronephrosis* \\
\hline QS & 170785 & T11A & 170586 & Failed & Indwelling urethral catheter, Bilat. Hydronephrosis \\
\hline NO & 050984 & L2A & 310385 & Success & Balanced Strainer 7 months post-op \\
\hline $\mathrm{HH}$ & 131084 & $\mathrm{~L} 3 \mathrm{C}$ & 091185 & Failed & Unbalanced strainer, Bilat. Hydronephrosis $* \dagger$ \\
\hline HI & 250687 & L3B & 160188 & Failed & Indwelling urethral catheter \\
\hline IF & 121186 & $\mathrm{~L} 3 \mathrm{C}$ & 040787 & Failed & Indwelling urethral catheter, ES was suggested \\
\hline NS & 180488 & $\mathrm{~L} 3 \mathrm{C}$ & 270888 & Failed & Indwelling urethral catheter, ES was suggested \\
\hline HM & 210388 & S1D & 090788 & Failed & Indwelling urethral catheter, ES was suggested \\
\hline SM & 100687 & $\mathrm{~S} 1 \mathrm{C}$ & 250688 & Failed & Indwelling urethral catheter, Bilat. Hydronephrosis: \\
\hline AA & 220382 & S2D & 260987 & Failed & Indwelling urethral catheter, ES was suggested $t$ \\
\hline
\end{tabular}

$\mathrm{DOI}=$ Date of injury; Level $=$ Neurological level; A, B, C, D, E = ASIA/IMSOP impairment scale; BNR $=$ Date of BNR.

*Catheterised later, †Died of renal failure, $\downarrow$ Had full urodynamic assessment pre and post procedure 
Table 2 Group II SCI patients who underwent external sphincterotomy (ES) after a primary bladder neck resection (BNR)

\begin{tabular}{|c|c|c|c|c|c|c|c|}
\hline Name & $D O I$ & Level & $B N R$ & Result & $E S$ & Result & Outcome/follow up \\
\hline $\mathrm{SH}$ & 191182 & C6A & 220783 & Failed & 301185 & Success & Balanced reflex tapper \\
\hline KA & 220783 & $\mathrm{C} 6 \mathrm{C}$ & 020984 & Failed & 270385 & Success & Balanced reflex tapper \\
\hline NA & 290387 & $\mathrm{C} 6 \mathrm{~B}$ & 010887 & Failed & 160188 & Success & Balanced reflex tapper \\
\hline $\mathrm{HH}$ & 210487 & T7A & 251287 & Failed & 260388 & Failed & Indwelling urethral catheter* \\
\hline $\mathrm{JF}$ & 040386 & $\mathrm{~T} 8 \mathrm{~A}$ & 050786 & Failed & 191086 & Success & Balanced reflex tapper \\
\hline $\mathrm{HJ}$ & 220187 & T9A & 251287 & Failed & 020488 & Failed & Indwelling urethral catheter* \\
\hline $\mathrm{AM}$ & 221287 & T9A & 180688 & Failed & 150888 & Failed & Indwelling urethral catheter* \\
\hline HA & 251286 & T10A & 260987 & Failed & 251287 & Success & Balanced reflex tapper \\
\hline $\mathrm{OH}$ & 250387 & $\mathrm{~T} 10 \mathrm{~A}$ & 301087 & Failed & 200888 & Failed & Indwelling urethral catheter* \\
\hline IA & 041186 & T10B & 040787 & Failed & 040787 & Failed & Indwelling urethral catheter* \\
\hline SG & 221283 & $\mathrm{~T} 12 \mathrm{C}$ & 130584 & Failed & 130385 & Success & Balanced reflex tapper \\
\hline AS & 040683 & L4C & 110184 & Failed & 010484 & Success & Balanced strainer \\
\hline
\end{tabular}

$\mathrm{DOI}=$ Date of injury; Level $=$ Neurological level; A, B, C, D, E = ASIA/IMSOP impairement scale; BNR $=$ Date of BNR; $\mathrm{ES}=$ Date of ES. $*$ Had full urodynamic assessment pre and post procedures

Table 3 Group III SCI patients who underwent external sphincterotomy (ES) only

\begin{tabular}{llllll}
\hline Name & DOI & Level & ES & Result & Outcome/follow up \\
\hline RA & 191083 & C5B & 180885 & Success & Balanced reflex tapper \\
MK & 030984 & L2A & 191185 & Success & Balanced strainer \\
\hline
\end{tabular}

$\mathrm{DOI}=$ Date of injury; Level $=$ Neurological level; A, B, C, D, E = ASIA/IMSOP impairement scale; ES = Date of ES

available for urodynamic assessment. Four patients (NS, HM, SM and AA) who had incomplete lower motor neurone lesions ended with permanent indwelling urethral catheters. Cystouroflowmetry showed a non-contractile, large capacity, high compliance detrusor in all of them with very poor flow if any.

The average pre BNR maximum urethral closure pressure was $51.7 \mathrm{~cm} \mathrm{H}_{2} \mathrm{O}$, and the average functional length was $2.2 \mathrm{~cm}$. The average post $\mathrm{BNR}$ maximum urethral closure pressure was $52.3 \mathrm{~cm} \mathrm{H} \mathrm{H}_{2} \mathrm{O}$, and the average functional length was $1.9 \mathrm{~cm}$. There was no significant difference in maximal urethral pressure or the functional length before and after BNR. One patient's IVU (SM) showed bilateral hydronephrosis. Overall, only two patients out of this group of 17, appear to have had some benefit following BNR without urodynamic evidence to this effect.

In group II, those who underwent ES after a primary BNR (12), seven patients had balanced reflex or strainer voiding at the time when the audit was conducted. Five patients who failed in achieving the said goal were invited for urodynamic assessment. They had upper motor neurone cord lesions and had indwelling urethral catheters at the time of examination. All five patients showed persistence of a relatively high maximum urethral closure pressure post ES with a range of $47.1-68.6 \mathrm{~cm} \mathrm{H}_{2} \mathrm{O}$ (average $=54.5 \mathrm{~cm}$ $\mathrm{H}_{2} \mathrm{O}$ ). Reflex detrusor contractions were noted on cystometry in these five patients with varying degrees of detrusor sphincter dysynergia (DSD), and three of them had strong reflex detrusor contractions (60$80 \mathrm{~cm} \mathrm{H}_{2} \mathrm{O}$ ) with unilateral vesico-ureteric reflux seen in one patient. One patient (IA) had his BNR and ES at the same time.

There was no report of antegrade ejaculation post BNR in group I patients, and there was one such report in group II patients post ES. Data relating to pre BNR ejaculation status was deficient.

\section{Discussion}

It is a well known fact that the scale of neuropathic bladder dysfunction and disability may not reflect in any degree the level of extent of the neurological lesion. ${ }^{3}$ Many previous investigators reported that the usual level of bladder outlet obstruction in SCI was at the external sphincter and advocated ES. ${ }^{4-6}$ Others tried BNR in an attempt to relieve this obstruction. ${ }^{7-9}$ Both groups of investigators reported conflicting results when the decision to carry out any of the procedures was oblivious of urodynamic studies. No two SCI cases behave in the same way, and the extent and level of injury gives only a very rough indication of what the eventual urological disability may be. ${ }^{3}$

Our audit has shown that the vast majority of SCI patients who underwent blind BNR did not benefit from this operation, regardless of their neurological level. They either required permanent indwelling catheterisation or had to undergo ES to achieve reflex voiding. The ejaculation mechanism in many of these patients must have been disturbed and their fertility reduced as a result. The issue of future fertility after BNR in our patients was not routinely addressed at the time of offering the procedure. Our audit 
confirming previous reports, ${ }^{10}$ also demonstrated that there was no correlation between the neurological level and urological findings. ${ }^{11,12}$ Therefore, attempts to carry out urological procedures based only on neurological examination are misguided. Urodynamic studies should be the cornerstone of assessment prior to offering these procedures. ${ }^{13}$

A recognised difficulty in the audit was the retrospective nature of the earlier part of it. Our method would have been more precise should we have had access to videourodynamics, which was not available. However, we do not think that the results of this audit would have been any different under the circumstances.

This audit confirms the urodynamic approach to the management of the neuropathic bladder as the current method for evaluation of lower urinary tract function. ${ }^{14}$ Assumptions about the likely behaviour of a particular neurological lesion as far as the neurological level or deficit are concerned, are likely to be erroneous regarding its neuropathic bladder status at any given time, and we disagree with such approaches. ${ }^{15}$ Evaluation of the target end organ, ie bladder and sphincter urodynamics, is an objective method of assessment upon which decisions for carrying out bladder or sphincter surgical procedures can confidently be based. BNR and ES are irreversible procedures, and the decision to perform them must be made carefully once all possibilities to restore continence have been exhausted, including pharmacological treatments, rehabilitation and clean intermittent catheterisation. ${ }^{16}$

In view of these findings, we advocate an individualised approach to rehabilitation of the neuropathic bladder in SCI. Different options of management should be offered depending on the patient's functional abilities, environment, and needs. Urodynamic assessment must precede bladder outlet surgery. We believe that if such an objective approach is undertaken, failure of these surgical procedures would be minimal. All SCI patients must undergo complete urodynamic evaluations before the institution of any type of therapy, and then at periodic intervals. $^{17}$

\section{Conclusions}

We conclude that blind BNR in the neuropathic bladder following spinal cord injury is obsolete. Such a practice should be avoided because of the futility of this procedure and the availability of objective urodynamic assessment. This blind surgical approach had a very high cost in terms of human suffering, time wasted, and material loss. The audit stresses the important value of urodynamics in Neuro-urology and neuropathic bladder rehabilitation. We also conclude that bladder outlet surgery must be preceded and guided by urodynamic studies. An individualised approach with an objective assessment should be implemented in SCI.

\section{References}

1 Bennett CJ. Editorial: The evolving importance of Neurourology and Urodynamics. J Urol 1996; 155: $275-276$.

2 Yokoyama $\mathrm{O}$ et al. Morphological and functional factors predicting bladder deterioration after SCI. J Urol 1996; 155: $271-274$.

3 O'Flynn JD. Early management of the neuropathic bladder in SCI. Paraplegia 1974; 12: $83-86$.

4 Watkins KH. The bladder function in spinal injury. $\mathrm{Br} J \mathrm{Surg}$ 1936; 23: $734-759$.

5 Ross JC, Gibbon NOK, Sunder GS. Division of the external urethral sphincter in the neuropathic bladder: A twenty years' review. British Journal of Urology 1976; 48: 649-656.

6 Light JK, Beric A, Wise PG. Predictive criteria for failed sphincterotomy in SCI. J Urol 1987; 138: $1201-1204$.

7 Emmett JL. Urinary retention from imblance of detrusor and vesical neck: treatment by transurethral resection. J Urol 1940; 43: $692-704$.

8 Emmett JL. Further observations in the management of cord bladder by transurethral resection. J Urol 1947; 57: 29 - 41 .

9 Gibbon NOK, Ross JC, Damanski M. Bladder neck resection in the paraplegic - report of over 100 cases. Int Paraplegia 1965; 2: $264-278$.

10 Lockhart JL, Vorstman B, Weinstein D, Politano VA. Sphincterotomy failure in neurogenic bladder disease. J Urol 1986; 135: $86-89$.

11 Lucas MG, Thomas DG. Lack of relationship of conus reflexes to bladder function after spinal cord injury. Br J Urol 1989; 63: 24 27.

12 Weiss DJ et al. Correlation of bladder function after spinal cord injury with initial perianal pinprick testing. J AM Paraplegia Soc 1994; 17(2): 106.

13 Wyndaele JJ. Correlation between clinical neurological data and urodynamic function in spinal cord injured patients. Spinal Cord 1997; 35: $213-216$.

14 Armin C, Bilijana R, Brigitte S, Volker D. Recovery of bladder function in patients with acute spinal cord injury: significance of ASIA scores and somatosensory evoked potentials. Spinal Cord 1997; 35: $368-373$.

15 Al-Ali M, Haddad L. A 10 year review of the endoscopic treatment of 125 spinal cord injured patients with vesical outlet obstruction: does bladder neck dyssynergia exist? Paraplegia 1996; 34: $34-38$.

16 Fontaine E et al., Reappraisal of endoscopic sphincterotomy for post-traumatic neurogenic bladder: A prospective study. J Urol 1996; 155: $277-280$.

17 Vapnek JM, Couillard DR, Stone AR. Is sphincterotomy the best management of SCI bladder? J Urol 1994; 151: 961 - 964. 